\title{
Determining the feasibility of harvesting invasive alien plant species for energy
}

AUTHORS:

Worship Mugido ${ }^{1}$

James Blignaut ${ }^{2}$

Matthew Joubert ${ }^{3}$

John De Wet ${ }^{4}$

Andrew Knipe ${ }^{5}$

Selmé Joubert ${ }^{3}$

Ben Cobbing ${ }^{6}$

James Jansen ${ }^{5}$

David Le Maitre ${ }^{7}$

Marius van der Vyfer ${ }^{8}$

\section{AFFILIATIONS:}

${ }^{1}$ Beatus Advisory Services,

Pretoria, South Africa

${ }^{2}$ Department of Economics, University of Pretoria, Pretoria,

South Africa

${ }^{3}$ EC Biomass Fuel Pellets (Pty) Ltd, Port Elizabeth, South Africa

${ }^{4}$ Facilities Management

Division: Forest Operations and Department of Forest and Wood Science, Stellenbosch University, Stellenbosch, South Africa

${ }^{5}$ Working for Water, Port Elizabeth, South Africa

${ }^{6}$ CSS (Pty) Ltd, Grahamstown, South Africa

${ }^{7}$ Natural Resources and the Environment, Council for Scientific and Industrial Research, Stellenbosch, South Africa

${ }^{8}$ Department of Botany, Nelson Mandela Metropolitan University, Port Elizabeth, South Africa

\section{CORRESPONDENCE TO:} James Blignaut

\section{EMAIL:}

jnblignaut@gmail.com

\section{POSTAL ADDRESS:}

Department of Economics, University of Pretoria, Private Bag X20, Hatfield 0028, South Africa

\section{DATES:}

Received: 30 Dec. 2013

Revised: 10 Mar. 2014

Accepted: 15 Mar. 2014

\section{KEYWORDS:}

woody biomass; invasive alien plants; biomass energy; externalities; financial cost; economic feasibility
Woody invasive alien plants (IAPs) are a threat to South Africa's water resources, biodiversity and land productivity. The impacts of IAPs were the main reason for the South African government to embark on a natural resource management public works programme called Working for Water (WfW), which was aimed at controlling IAPs in a cost-effective yet labour-intensive way. At the same time, the high biomass of these species presents opportunities for synergies between the clearing of IAPs and the generation of biomassbased energy. The purpose of this study was to determine the cost of harvesting and extracting, chipping, and transporting the biomass, and also to determine the financial and economic feasibility of such an exercise from a commercial perspective. Sampling of the biomass was done at 31 representative sites within the Nelson Mandela Metropolitan Municipality, South Africa. The cost of the operation was carefully monitored, documented and reported at each stage, and compared to the cost of replacing the thermal coal currently used by industry within this municipality. The project proved to be financially viable, but only when the energy entrepreneur forms a partnership with the WfW programme, and then only under specific conditions. The project has, however, very high socio-economic returns with respect to a reduction in environmental externalities and job creation.

\section{Introduction}

Woody invasive alien plants (IAPs) pose significant direct threats to South Africa's ecosystems and the services they provide, including water, land productivity and biodiversity. ${ }^{1-5}$ These threats are being addressed by the Working for Water (WfW) programme which aims to control invasions as well as provide work and training for unskilled people. The biomass produced during control operations could be used to generate energy, potentially fully or partially offsetting the costs of control.

The mining, transportation and combustion of coal for the purposes of generating electricity has negative impacts on the environment and human health. Studies have shown that some of these effects include the impact of air pollution on human health, the impact of climate change and the environmental impact on water quantity and quality and on biodiversity. ${ }^{6-11} \mathrm{~A}$ number of studies have quantified the externality costs of mining coal and transporting it to the Kusile coal-fired power station in eMalahleni, Mpumalanga Province of South Africa ${ }^{6-9}$ (see also Letsoalo et al. ${ }^{12}$ and $0^{\prime}$ Farrell et al. ${ }^{13}$ for a discussion on the value of natural resources and the difficulties of their quantification). These studies estimated the externalised cost on both the environment and humans of mining and transporting coal to be between ZAR6358 million and ZAR12 690 million per annum. While extremely large in and by themselves, these figures still exclude some externalities like noise pollution, damage to roads and damage caused by ash lagoons on water resources.

The externality costs associated with using coal for electricity generation purposes justify an investigation into the viability of using IAPs for bioenergy production. In particular, the Nelson Mandela Metropolitan area in the Eastern Cape Province of South Africa depends on coal to generate electricity to meet its energy needs. The unit cost of coal has increased noticeably because of increasing transport costs and a decline in the quality of the coal. The combination of the negative externalities and the rising price of coal may make the utilisation of (woody) IAPs for heat and power generation economically viable. While it is generally recognised that the use of biomass for energy generation has many positives, including low ash and low flue gas emissions, there are also recognised risks, particularly uncertainties about the sustainable supply of high-quality biomass and the cost of its delivery. ${ }^{14}$

The use of IAPs for energy purposes has the potential to reduce both the negative externalities caused by coal-fired energy generation and their harmful effects on the environment. In addition, the use of IAPs for bioenergy production will contribute to reducing invasions and restoring the invaded ecosystems. The benefits of clearing IAPs include a reduction in both fire protection costs and damage to infrastructure as a result of wildfires, the conservation of biodiversity and ecosystem resilience, an increase in water quantity and quality, improved river system services, social development and poverty alleviation, job creation, economic empowerment and training, flood control, and the containment of erosion and a decrease in the siltation of dams. ${ }^{3,15-18}$ Linking a public works programme like WfW with an industrial sector activity, such as the generation of electricity, has the added benefit of providing sustainability to the job creation process within the so-called 'green economy'. It elevates the WfW project from being a poverty reduction initiative with environmental benefits, to one that is also integrally linked to the mainstream industrial economy.

Although there are these clear synergies between the benefits of control, it is essential to establish the viability of such a venture. In this study, we determined the direct financial cost of harvesting (i.e. felling and extracting),

\section{HOW TO CITE:}

Mugido W, Blignaut J, Joubert M, De Wet J, Knipe A, Joubert S, et al. Determining the feasibility of harvesting invasive alien plant species for energy. S Afr J Sci. 2014;110(11/12), Art. \#2013-0397, 6 pages. http://dx.doi.org/10.1590/ sajs.2014/20130397 
chipping and transporting woody IAP biomass in the Nelson Mandela Metropolitan area to a site for energy generation purposes. We also determined the overall financial and economic feasibility of such an exercise.

\section{Materials and methods}

\section{Background and rationale}

The WfW programme is currently running a number of IAP clearing projects within a $50-\mathrm{km}$ radius of the Coega Industrial Development Zone (Coega IDZ) in the Nelson Mandela Metropolitan area. A biomass processing plant has also been established in the Coega IDZ. This situation presented an opportunity to investigate the synergies between the clearing of IAPs and the bioenergy plant within the Nelson Mandela Metropolitan area. A joint venture between the bioenergy power (pelletising) plant and WfW was formed to conduct a trial project. This trial project entailed WFW clearing IAPs in four WfW project areas and the bioenergy power plant chipping and transporting the material to a weigh bridge, and carefully monitoring and documenting all costs, moisture levels, species composition and densities of the IAPs harvested. Biomass-based electricity generation requires a constant supply of biomass. Yet, the biomass source is finite. This necessitates that (1) the method of harvesting and transporting the biomass must be as efficient as possible and (2) both the area of supply and the period within which the material can be harvested are constrained. Therefore the study area was limited to a 50-km radius and a project period of 60 months was assumed. No regrowth was factored in, as that would negate the benefits of harvesting IAPs. This source, however, provides the project developer with a window of opportunity to develop other, sustainable, sources of biomass supply without having to wait.

\section{Selection of harvesting sites}

A desktop analysis was conducted using ArcView geographic information system (GIS) software to characterise the woody alien vegetation biomass within the boundaries of the study area. Polygons of alien vegetation were digitised from recent (late-2009) aerial photography and the species composition and density were classified and mapped. The biomass models developed by Le Maitre et al..$^{19}$ were then used to estimate the available biomass based on this classification.

This desktop analysis was then filtered using an area-based IAP clearing suitability index. The index was based on five factors: slope, distance from the pelletising plant, distance from an access road, biomass volume and influence of riparian area. Windrows were included but treated separately. Maps ranking the suitability of the study area based on the above-mentioned parameters were produced. ${ }^{20}$ The 15364 polygons were ranked in terms of their suitability and the ones that scored poorly were eliminated as there was a general consensus among stakeholders that it would be unlikely to be economically viable in the long term to extract biomass from these polygons. This exclusion resulted in a reduction in the number of polygons to approximately 650 .

Field verification was done on 286 of these pre-selected polygons noting the type of species, age of trees, tree density, the slope, distance from the road and also distance from the riparian zone for each polygon. This observed information was then compared to the information contained in the original GIS data set to ascertain the correctness of the GIS database through a process of 'ground truthing'. Field verification is essential because it is very difficult to accurately identify actual species in a given polygon based solely on aerial photography, particularly for acacias, and to refine the estimates of density and tree size. The field verification thus increased confidence in the biomass determination.

The IAPs were then harvested on $5 \%$, or 31 , of the 622 contiguous polygons. Of the 622 polygons, 81 were randomly selected for field trials using a GIS random selection function to determine which sites should be harvested. This number was more than is required but the extras were included to make provision for farmers or landowners who did not want portions of their land to be cleared.

\section{Harvesting, chipping and transporting methods}

The harvesting was done using two methods. Method 1 involved felling and stacking the branches on the roadside and then chipping them. Method 2 entailed felling and hand-feeding the branches into the chipper directly, avoiding the stacking. Felling was done using chainsaws and/or brush cutters depending on the size of the trees. Felling and extraction was done by three teams, each comprising 22 people. The chipper that was used for both methods is a Bandit 250XP (Port Elizabeth, South Africa).

A truck brought two empty $28-\mathrm{m}^{3}$ bins to the site, one on the truck and another on a trailer. The bins usually were placed close to the stacked branches or where the branches would be stacked. The chipper would then chip the biomass directly into the bins. The chipping team consisted of one supervisor, two chipper operators and eight general workers. The team was responsible for hand-feeding the chipper and managing the chipping process. Once the bins were full, the truck would collect them and take them to the weigh bridge. The weight of each bin and the transportation costs were then passed on to the data collection team. Samples were taken from each bin and sent to a laboratory to determine the moisture content and calculate the dry mass.

\section{Data collection methods}

The data collection team (with the help from the chipping team, felling and extraction team, and project manager) developed data logging forms for felling and extraction and chipping. These were completed by the respective supervisors in charge of felling and extraction, and chipping. Information recorded on the forms included the number of workers, amount of fuel used, number of days worked per site, and chipping hours. The records were checked daily to establish whether they were completed correctly.

\section{Calibrating the G/S data}

Non-destructive mensuration was also to supplement the remote sensing and field harvesting, and refine the estimates of the available biomass in the study area. As in similar studies ${ }^{21-23}$ on invasive Acacia species, 'non-standard, non-plantation and non-commercial forestry concepts' were required. ${ }^{21}$ We noted, however, that the size (age), density and species distribution of the stands had changed and thus the biomass composition had changed from that found in previous studies. It was critical to have accurate estimates of the available biomass in the study area because the trial demonstrated that the cost of harvesting, chipping and transporting biomass is very sensitive to the volume of biomass. Furthermore, if the amount of biomass available in the study area is not well known or if there is insufficient biomass it may not be worthwhile to undertake such a project.

The objective of the mensuration for this trial was to estimate the standing biomass of the complete tree, inclusive of all tree components, as well as the biomass of whole stands. Allometric measurements were taken on a total of 103 different polygons, including all the field harvesting sites. A representative transect of $50 \mathrm{~m} \times 4 \mathrm{~m}$ was selected within each polygon based on its species composition, density, tree age and growth form. The site was briefly described and photographs were taken for reference purposes. Necromass (standing dead wood) was not measured. Diameter measurements were taken according to the tree type: medium trees had their diameter measured at knee height ( $0.5 \mathrm{~m}$ above ground level) and large trees had their diameter measured at breast height (1.3 $\mathrm{m}$ above ground level). Tall (large) trees included Eucalyptus spp., Acacia mearnsii and Pinus species, with height also measured for pines. Medium trees included Acacia cyclops, Acacia saligna and Acacia Iongifolia. The mass of each tree was determined and used to calculate species-specific allometric equations based on the corresponding stem diameters. These equations were then used with the sample of diameters to estimate the standing biomass in each polygon. As a result of the limited contribution of Pinus spp. to the biomass of the area, standard plantation volume equations with conversion factors were applied to calculate oven-dry mass for the whole tree. 


\section{Results and discussion}

Harvesting and extraction, and chipping and transport costs

There is a wide range in the cost of harvesting and extraction, and chipping and transportation of biomass per species class (Table 1). The Acacia longifolia class has the highest harvesting and extraction costs, while the Acacia spp. class has the lowest harvesting and extraction costs. The variance in the cost of harvesting and extraction can be attributed mainly to differences in stand densities, tree sizes and the slope in the study area. The Eucalyptus-Acacia-Pine class had the highest chipping costs, while the Acacia saligna class had the lowest chipping costs. The Eucalyptus-Acacia class showed the greatest variance in terms of transport costs. The cost of transport is based on the actual realised (invoiced) cost of transporting the biomass from the harvesting site, and the distances varied between $30 \mathrm{~km}$ and $50 \mathrm{~km}$. The unit costs varied between ZAR1.09/km/t and ZAR4.63/ $/ \mathrm{km} / \mathrm{t}$ with a weighted average of approximately ZAR2.50/km/t. This cost is much higher than the industry average of approximately ZAR1.1/km/t (Road Freight Association 2013, verbal communication, September 16) because of the method used, namely outsourcing the transport to a contractor who uses non-customised bins.

The harvesting and extraction cost generally constitutes most of the overall cost, followed by chipping and then transport (Figure 1). The chipping cost is particularly high for the Eucalyptus-Acacia-Pine and Acacia-Pine classes. These high chipping costs were a result largely of operational issues - including road conditions and related challenges with respect to access and transport - that is, conditions that were site specific and not determined by the species class.

\section{Allometry biomass data verification}

The findings from the in-field verification, detailed in-field mensuration, destructive allometry and the actual harvested biomass tonnages were used to confirm the availability of the biomass and calibrate the available biomass GIS data values. The net result was that each of the mapped invasion classes was allocated a relevant biomass value (Table 2). The allometry species class biomass values show a variance of between $-22 \%$ and $+16 \%$ from the allocated class biomass values. The relatively high variances within species classes for allometry biomass tonnage results reflect the in-field realities of varying densities, ages and previous selective harvesting by wood cutters. The variances observed justified the in-field harvesting of the biomass to improve the credibility of the estimated volume of biomass availability. Based on the biomass distribution and densities in the GIS database, after being calibrated with the information from the harvested sites, there is approximately
551550 tonnes of readily accessible woody IAPs scattered across 8900 ha within a $50-\mathrm{km}$ radius of the Coega IDZ.

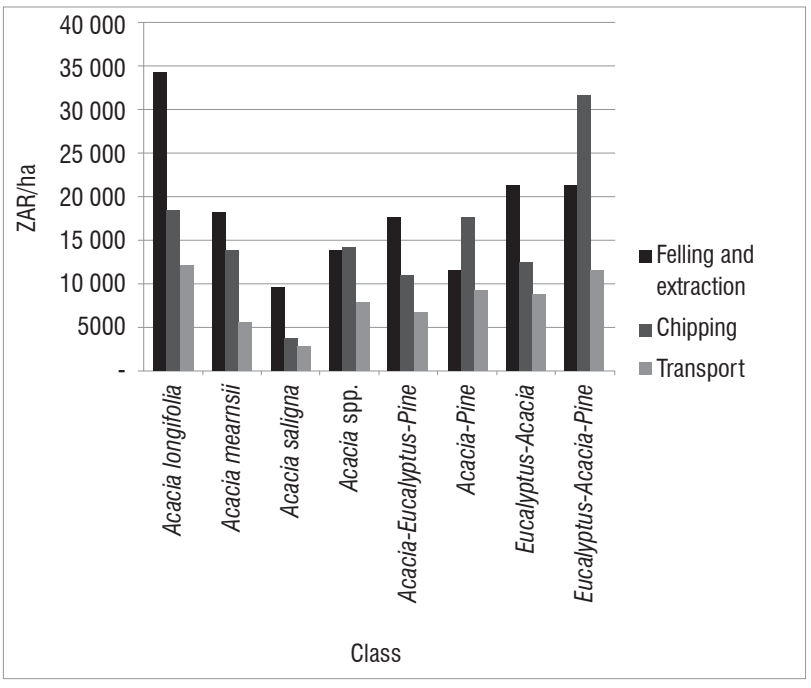

Figure 1: A comparison of the felling and extraction, chipping and transport costs per species class.

\section{Feasibility assessment}

Eight scenarios were developed to assess the feasibility of harvesting IAPs for energy purposes under different conditions. Each scenario had three different pricing options (the main inputs and assumptions of the model are presented in the Appendix). The eight scenarios are:

1. All activities are outsourced to third parties, and all costs are paid for by energy entrepreneur.

2. All activities are outsourced to third parties, but harvesting and extraction cost is carried by the Natural Resource Management (NRM) programmes (i.e. WfW).

3. As in Scenario 2, but biomass is allowed to dry in-field for 60 days.

4. Transporting is done in-house, all other activities are outsourced to third parties, but harvesting and extraction cost is carried by the NRM programmes.

5. Transporting and chipping are done in-house, but harvesting and extraction cost is carried by the NRM programmes.

Table 1: The costs of harvesting, chipping and transporting biomass

\begin{tabular}{|c|c|c|c|c|c|c|}
\hline \multirow{3}{*}{ Class } & \multicolumn{6}{|c|}{ Cost (ZAR/ha) } \\
\hline & \multicolumn{2}{|c|}{ Harvesting and extraction } & \multicolumn{2}{|c|}{ Chipping } & \multicolumn{2}{|c|}{ Transport } \\
\hline & Minimum & Maximum & Minimum & Maximum & Minimum & Maximum \\
\hline Acacia longifolia & 25403 & 43487 & 13678 & 23340 & 9513 & 14853 \\
\hline Acacia mearnsii & 15431 & 21097 & 5831 & 22045 & 2433 & 8834 \\
\hline Acacia saligna & 5046 & 14274 & 2545 & 5081 & 2579 & 3089 \\
\hline Acacia spp. & 7726 & 20093 & 8696 & 20009 & 4176 & 11773 \\
\hline Acacia-Eucalyptus-Pine & 13812 & 21523 & 10976 & 11285 & 6597 & 6951 \\
\hline Acacia-Pine & 8135 & 15084 & 8567 & 27027 & 4874 & 13819 \\
\hline Eucalyptus-Acacia & 8644 & 34502 & 3863 & 21245 & 1468 & 16522 \\
\hline Eucalyptus-Acacia-Pine & 19719 & 23083 & 19957 & 43312 & 10784 & 12721 \\
\hline
\end{tabular}

Note: The species are in order of descending dominance. 
6. As in Scenario 5, but biomass is allowed to dry in-field for 60 days.

7a. As in Scenario 6, but the biomass cost payable by the pelletising plant to NRM is increased from ZAR100/tonne (Scenarios 1-6), to ZAR150/tonne.

\section{7b. As in Scenario 7a, but limiting the operation to 100000 tonnes.}

The costs of all the scenarios were based on the actual data that was collected throughout the course of the project, except for the transport costs of Scenarios 4-6 which were based on the Road Freight Association's information. The chipping costs for Scenarios 5 and 6 were based on the default costs of the manufacturer of the chippers (Bandit). The price for coal was set at $4.7 \mathrm{c} / \mathrm{MJ}$, which is $95 \%$ of the value of thermal coal landed in the municipal area.

\section{Feasibility assessment results}

Scenario 1, the scenario under which the energy entrepreneur has to carry all the cost, is not financially viable (Table 3). Scenario 6 offers the highest net present value for the net income to the energy entrepreneur. Under this scenario the energy entrepreneur would be responsible for all chipping and transport activities in-house, allow the biomass to dry for 60 days in-field, and compensate the WfW ZAR100/t (wet) biomass harvested (felled and extracted to road side). Scenario 6, however, implies an increase in clearing cost to the WfW from a norm of about ZAR6000/ha to ZAR11 200/ha which does not meet the WfW mandate of cost-effective clearing of IAPs. This is despite the large externality benefits as a result of the biomass replacing coal as energy feedstock. The introduction of Scenario $7 \mathrm{a}$, which is the same as Scenario 6 except for an increase in the cost of the biomass to ZAR150/tonne, reduces the cost of clearing for the WfW to ZAR8200/ha. The estimates with respect to the externality costs only refer to the use of coal for electricity generation purposes in the Highveld of South Africa as point of reference. This approach excludes the externality cost associated with the transport of the coal to the Nelson Mandela Metropolitan area. It also excludes, as an addition, the externality benefits associated with clearing IAPs. It was decided to exclude these benefits as they are very site specific and because a harvesting plan and method had not been developed; it would be erroneous to include them.

Scenarios $7 \mathrm{a}$ and $7 \mathrm{~b}$ indicate the economic feasibility of the operation without comparing it with the cost of coal. Using a calorific value of $11.5 \mathrm{MJ} / \mathrm{kg}$ for biomass with a moisture content of $35 \%$ (i.e. freshly cut) and $13.6 \mathrm{MJ} / \mathrm{kg}$ for biomass with a moisture content of $25 \%$ (i.e. after an in-field drying period of 60 days), the energy unit costs for all the scenarios were estimated (Figure 2). While the unit costs of Scenarios 7a (ZAR28.7/GJ) and 7b (ZAR31/GJ) exceed that of Scenario 6 (ZAR24.8/GJ), they are still much lower than that of coal (ZAR49/GJ), making them potentially economically feasible.

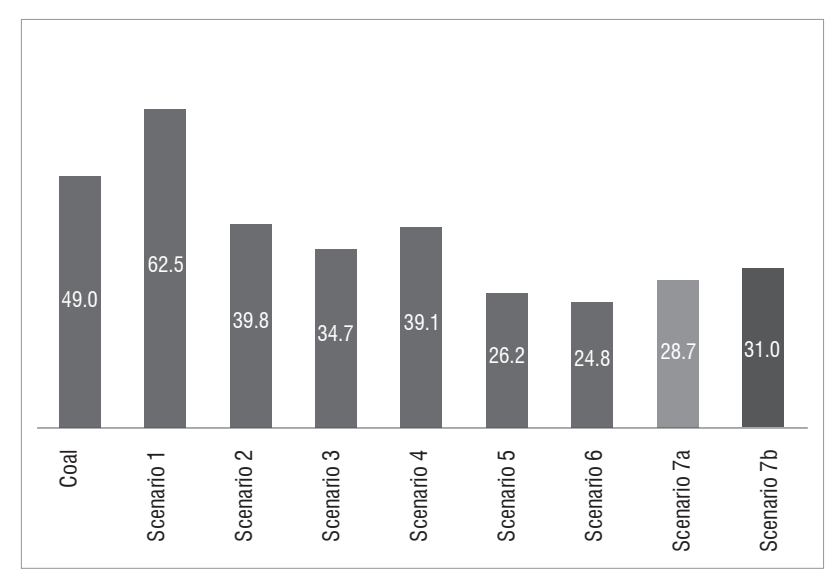

Figure 2: Unit cost (ZAR/GJ) of harvesting and transporting (woody) invasive alien plants within a radius of $50 \mathrm{~km}$ to a central plant for energy purposes.

\section{Conclusion}

Invasive alien plants are widespread in South Africa and pose a major threat to the country's water sources and biodiversity as well as threatening lives and infrastructure by being fire prone. At the same time, South Africa is highly dependent on coal for its energy needs. We investigated the economic feasibility of using woody IAPs as a source of bioenergy in the Nelson Mandela Metropolitan Municipality. The total cost of the operation could be as high as ZAR62/GJ, which compares unfavourably to that of coal at ZAR49/GJ. If the WfW programme bears a portion of the cost, the direct cost to the energy entrepreneur declines to between ZAR25/GJ and ZAR31/GJ depending on the scenario. Under such conditions, the harvesting of IAPs for bioenergy purposes is both financially and economically viable given the large, positive externalities associated with such an operation, namely replacing fossil fuels, clearing IAPs and generating employment.

In sum, the project is financially viable when done in conjunction with the WfW programme and has high socio-economic returns with respect to a reduction in environmental externalities and the creation of job opportunities.

Table 2: Comparison of allometry biomass estimation and allocated species class biomass

\begin{tabular}{|c|c|c|c|}
\hline Mapped species class & $\begin{array}{c}\text { Biomass (tonnes/ha) } \\
\text { at } 100 \% \text { cover: } \\
\text { Mean values: } \\
\text { Allometry }\end{array}$ & $\begin{array}{c}\text { Biomass (tonnes/ha) } \\
\text { at } 100 \% \text { cover: } \\
\text { Mean values: } \\
\text { Harvested }\end{array}$ & $\begin{array}{l}\text { Percentage difference } \\
\text { (\%) }\end{array}$ \\
\hline Acacia-Eucalyptus-Pine & 63.80 & 56.58 & $13 \%$ \\
\hline Acacia-Pine & 82.31 & 71.97 & $14 \%$ \\
\hline Acacia longifolia & 51.30 & 58.48 & $-12 \%$ \\
\hline Acacia mearnsii & 35.77 & 31.73 & $13 \%$ \\
\hline Acacia saligna & 18.10 & 23.20 & $-22 \%$ \\
\hline Acacia spp. & 96.34 & 83.14 & $16 \%$ \\
\hline Eucalyptus-Acacia-Pine & 75.96 & 86.51 & $-12 \%$ \\
\hline Eucalyptus-Acacia & 79.71 & 84.94 & $-6 \%$ \\
\hline
\end{tabular}

Note: The species are in order of descending dominance. 
Table 3: Summary of results of the feasibility model

\begin{tabular}{|c|c|c|c|c|c|c|c|c|}
\hline & 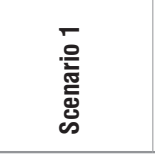 & 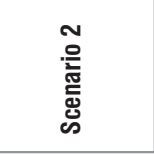 & $\begin{array}{l}\text { m } \\
\text { 은 } \\
\text { 心్ } \\
\text { 心 }\end{array}$ & 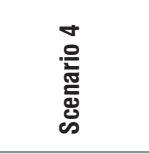 & 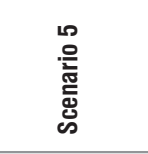 & $\begin{array}{l}\text { D } \\
\text { 잃 } \\
\text { 心्ञ } \\
\text { 心 }\end{array}$ & 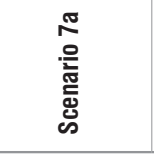 & 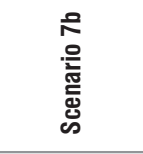 \\
\hline Total tonnes & 524467 & 524467 & 454538 & 524467 & 524467 & 454538 & 454538 & 86667 \\
\hline $\begin{array}{l}\text { NPV of entrepreneur's OpEx } \\
\text { (ZAR) }\end{array}$ & 298663916 & 168807285 & 142238448 & 135912623 & 43187901 & 37290171 & 37290171 & 8132039 \\
\hline $\begin{array}{l}\text { NPV of biomass cost } \\
\text { (ZAR) }\end{array}$ & 47040810 & 47040810 & 48213421 & 47040810 & 47040810 & 48213421 & 72320132 & 14511895 \\
\hline $\begin{array}{l}\text { NPV of total CapEx } \\
\text { (ZAR) }\end{array}$ & 19256768 & 12087949 & 12087949 & 41252728 & 67605633 & 67605633 & 67605633 & 13941272 \\
\hline $\begin{array}{l}\text { NPV of gross income } \\
\text { (ZAR) }\end{array}$ & 252201897 & 252201897 & 258488669 & 252201897 & 252201897 & 258488669 & 258488669 & 51868828 \\
\hline $\begin{array}{l}\text { Net income (NPV) (excl. } \\
\text { externalities) (ZAR) }\end{array}$ & -112759596 & 24265854 & 55948851 & 27995736 & 94367554 & 105379443 & 81272733 & 15283621 \\
\hline IRR (excl. externalities) & NA & $5.7 \%$ & $9.9 \%$ & $2.2 \%$ & $3.7 \%$ & $4.0 \%$ & $3.3 \%$ & $6.2 \%$ \\
\hline $\begin{array}{l}\text { NPV of externality (average } \\
\text { ZAR) }\end{array}$ & 678240873 & 678240873 & 695147747 & 678240873 & 678240873 & 695147747 & 695147747 & 139489669 \\
\hline $\begin{array}{l}\text { Net income (NPV) (incl. } \\
\text { externalities) (ZAR) }\end{array}$ & 565481277 & 702506727 & 751096598 & 706236609 & 772608427 & 800527191 & 776420480 & 154773291 \\
\hline IRR (incl. externalities) & $129.1 \%$ & $511.8 \%$ & $811.6 \%$ & $33.0 \%$ & $20.6 \%$ & $21.4 \%$ & $20.7 \%$ & $63.9 \%$ \\
\hline $\begin{array}{l}\text { NPV of biomass cost/tonne } \\
\text { (ZAR) }\end{array}$ & 90 & 90 & 106 & 90 & 90 & 106 & 82 & 94 \\
\hline Discounted OpEx/tonne (ZAR) & 569 & 322 & 313 & 259 & 82 & 82 & 159 & 167 \\
\hline $\begin{array}{l}\text { Total initial CapEx requirement } \\
\text { (ZAR) }\end{array}$ & 14063500 & 11540000 & 11540000 & 40440000 & 66745000 & 66745000 & 66745000 & 13490000 \\
\hline
\end{tabular}

NPV, net present value; OpEx: operating expenditure; CapEx: capital expenditure; IRR, internal rate of return

\section{Acknowledgements}

We acknowledge funding from Working for Water and the Industrial Development Corporation. We also thank two anonymous reviewers for their comments. Calculations and factors were reproduced with permission from the Road Freight Association. These figures were derived from the Vehicle Costing Schedule (VCS) - Edition 47 (April 2013). Neither the Road Freight Association nor the authors are responsible for any misuse of the data or assumptions quoted in this article.

\section{Authors' contributions}

W.M. was responsible for all data collection, data analysis and the compilation of the text. J.B. was responsible for the project management, data analysis and the compilation of the text. M.J. was responsible for the site management, client and landowner liaison and technical analysis. J.d.W was responsible for the verification of the data in relation to forestry benchmark statistics. A.K. was responsible for managing the WfW harvesting and extraction teams. S.J. was co-responsible for the allometry estimates. B.C. was responsible for the GIS analysis. J.J. was responsible for landowner liaison from a WfW perspective. D.L.M. was responsible for the GIS and allometry calibration. M.v.d.V. was coresponsible for the allometry estimates.

\section{References}

1. Blignaut JN, Marais C, Turpie J. Determining a charge for the clearing of invasive alien plant species to augment water supply in South Africa. Water SA. 2007;33(1):27-34.

2. Turpie JK, Marais C, Blignaut JN. Evolution of a Payments for Ecosystem Services mechanism that addresses both poverty and ecosystem service delivery in South Africa. Ecol Econ. 2008;65:788-798. http://dx.doi. org/10.1016/j.ecolecon.2007.12.024

3. Van Wilgen BW, Reyers B, Le Maitre DC, Richardson DM, Schonegevel L. A biome-scale assessment of the impact of invasive alien plants on ecosystem services in South Africa. J Environ Manage. 2008;89:336-349. http://dx.doi. org/10.1016/j.jenvman.2007.06.015

4. Le Maitre DC, Gaertner M, Marchante E, Ens EJ, Holmes PM, Pauchard A et al. Impacts of introduced Australian acacias on ecosystem services and functions, and options for restoration. Divers Distrib. 2011;17:1015-1029. http://dx.doi.org/10.1111/j.1472-4642.2011.00816.x 
5. Crookes D, Blignaut JN, De Wit M, Esler K, Le Maitre D, Milton S, et al. Dynamic modelling to assess economic viability and risk trade-offs for eight ecological restoration projects in a water-scarce developing country. J Environ Manage. 2013;120:138-147. http://dx.doi.org/10.1016/j.jenvman.2013.02.001

6. Riekert JW, Koch SF. Projecting the external health costs of a coal-fired power plant: The case of Kusile. J Energy South Afr. 2012;23(4):52-66.

7. Blignaut JN. Climate change: The opportunity cost of Medupi and Kusile power stations. J Energy South Afr. 2012;23(4):67-75.

8. Inglesi-Lotz R, Blignaut JN. Estimating the opportunity cost of water for the Kusile and Medupi coal-fired electricity power plants in South Africa. J Energy South Afr. 2012;23(4):76-84.

9. Nkambule NP, Blignaut JN. The external costs of coal mining: the case of collieries supplying Kusile power station. J Energy South Afr. 2012;23(4):85-93.

10. Epstein PR, Buonocore JJ, Eckerle K, Hendryx M, Stout III BM, Heinberg R, et al. Full cost accounting for the life cycle of coal in 'Ecological Economics Reviews'. Ann NY Acad Sci. 2011;1219:73-98. http://dx.doi.org/10.1111/ j.1749-6632.2010.05890.x

11. Amerasinghe N, Porter S. Fossilized thinking. The World Bank, Eskom, and the real cost of coal. Washington DC: CIEL; 2011.

12. Letsoalo A, Blignaut J, De Wet T, De Wit M, Hess S, Tol RSJ, et al. Triple dividends of water consumption charges in South Africa. Water Resour Res. 2007;43(5):W05412. http://dx.doi.org/10.1029/2005WR004076

13. O'Farrell P, Le Maitre D, De Lange W, Reyers B, Blignaut J, Milton S, et al. The possibilities and pitfalls presented by a pragmatic approach to ecosystem service valuation in an arid biodiversity hotspot. J Arid Environ. 2011;75:612623. http://dx.doi.org/10.1016/j.jaridenv.2011.01.005

14. Bowyer J. Life cycle impacts of heating with wood in scenarios ranging from home and institutional heating to community scale district heating systems. Minneapolis, MN: Dovetail Partners, Inc.; 2012.
15. Marais C, Eckert J, Green C. Utilisation of invaders for secondary industries, a preliminary assessment. Best management practices for preventing and controlling invasive alien species - Symposium proceedings. Cape Town: Working for Water Programme; 2000.

16. Blignaut J, Mander M, Schulze R, Horan M, Dickens C, Pringle K, et al. Restoring and managing natural capital towards fostering economic development: Evidence from the Drakensberg, South Africa. Ecol Econ. 2010;69:1313-1323. http://dx.doi.org/10.1016/j.ecolecon.2010.01.007

17. De Groot R, Blignaut JN, Van Der Ploeg S, Aronson J, Elmqvist T, Farley J. Benefits of investing in ecosystem restoration. Conserv Biol. 2013;27(6):1286-1293. http://dx.doi.org/10.1111/cobi.12158

18. Blignaut J, Aronson J, De Groot R. Restoration of natural capital: A key strategy on the path to sustainability. Ecol Eng. 2013;65:54-61. http://dx.doi. org/10.1016/j.ecoleng.2013.09.003

19. Le Maitre DC, Van Wilgen BW, Chapman RA, McKelly DH. Invasive plants and water resources in the Western Cape: Modelling the consequences of a lack of management. J Appl Ecol. 1996;33:161-172. http://dx.doi. org/10.2307/2405025

20. Cobbing B. Estimation of alien plant biomass for EC biomass fuel pellets. For the Working for Water Project areas within a 50km zone around Port Elizabeth. Grahamstown: CSS; 2012.

21. Van Laar A, Theron JM. Equations for predicting the biomass of Acacia cyclops and Acacia saligna in the Western and Eastern Cape regions of South Africa: Part 1: Tree-level models. S Afr For J. 2004;201:25-34.

22. Van Laar A, Theron JM. Equations for predicting the biomass of Acacia cyclops and Acacia saligna in the Western and Eastern Cape regions of South Africa: Part 2: Stand level models. S Afr For J. 2004;201:35-42.

23. Theron JM, Van Laar A, Kunneke A, Bredenkamp BV. A preliminary assessment of utilizable biomass in invading Acacia stands on the Cape coastal plains. S Afr J Sci. 2004;100:123-125.

Appendix: Summary of key inputs and assumptions into the feasibility model

\begin{tabular}{|c|c|c|c|c|c|c|c|c|}
\hline \multicolumn{9}{|c|}{$\begin{array}{l}\text { Key assumptions kept constant for S } \\
\text { Scenario } 7 \mathrm{~b}\end{array}$} \\
\hline Term: & \multicolumn{8}{|l|}{60 months } \\
\hline Discount rate: & \multicolumn{8}{|l|}{$4 \%$ p.a. } \\
\hline Cost scenario: & \multicolumn{8}{|c|}{ Low, i.e. $85 \%$ of experimental cost to allow for improvements in efficiency and economies of scale } \\
\hline Cost of biomass: & \multicolumn{8}{|c|}{ ZAR100/wet tonne and ZAR118/dry tonne } \\
\hline \multicolumn{4}{|l|}{ Price scenario: } & ZAR/MJ & $\begin{array}{c}\mathrm{MJ} / \mathrm{kg} \\
(\sim 35 \% \text { moisture })\end{array}$ & $\begin{array}{c}\mathrm{MJ} / \mathrm{kg} \\
(\sim 25 \% \text { moisture })\end{array}$ & ZAR/wet tonne & ZAR/dry tonne \\
\hline & \multicolumn{3}{|c|}{ Pessimistic (85\% of realistic) } & 0.040 & 11.5 & 13.6 & 455.7 & 538.9 \\
\hline & \multicolumn{3}{|c|}{ Realistic (95\% of coal equiv. (27 MJ/kg)) } & 0.047 & 11.5 & 13.6 & 536.1 & 634.0 \\
\hline & \multicolumn{3}{|c|}{ Optimistic ( $115 \%$ of realistic) } & 0.054 & 11.5 & 13.6 & 616.6 & 729.1 \\
\hline \multirow[t]{7}{*}{ Biomass: } & Cluster & Distance (km) & Hectares & Total tonnes & Tonnes/month & Months to clear & Number of teams & Hectare/month \\
\hline & Area 1 & 40 & 2206 & 138370 & 6490 & 22 & 25 & 100 \\
\hline & Area 2 & 40 & 3583 & 223574 & 10354 & 22 & 40 & 163 \\
\hline & Area 3 & 40 & 240 & 15176 & 18242 & 1 & 70 & 240 \\
\hline & Area 4 & 65 & 451 & 30784 & 19025 & 2 & 70 & 225 \\
\hline & Area 5 & 65 & 1539 & 88183 & 12360 & 8 & 50 & 192 \\
\hline & Area 6 & 65 & 410 & 28380 & 8215 & 4 & 30 & 102 \\
\hline
\end{tabular}

Please note that harvesting and extraction is defined as up to roadside. Cost of biomass refers to the amount per tonne paid to the Natural Resource Management programmes (i.e. WfW) for the biomass extracted to roadside. 